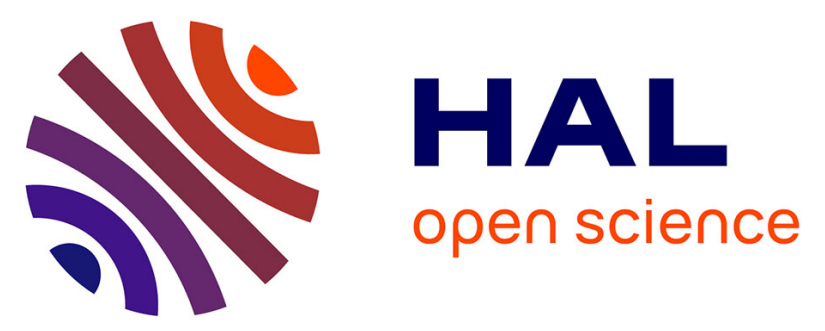

\title{
Is physical fitness associated with the type of attended school? A cross-sectional analysis among 20.000 adolescents.
}

\author{
Martine Duclos, Philippe Lacomme, Celine Lambert, Bruno Pereira, Libo
} Ren, Gerard Fleury, Hervé Ovigneur, Thibault Deschamps, Nicole Fearnbach, Jeremy Vanhelst, et al.

\section{To cite this version:}

Martine Duclos, Philippe Lacomme, Celine Lambert, Bruno Pereira, Libo Ren, et al.. Is physical fitness associated with the type of attended school? A cross-sectional analysis among 20.000 adolescents.. Journal of Sports Medicine and Physical Fitness, 2022, The Journal of Sports Medicine and Physical Fitness, 62 (3), pp.404-411. 10.23736/S0022-4707.21.12203-0 . hal-03183932

\section{HAL Id: hal-03183932 \\ https://hal.univ-lille.fr/hal-03183932}

Submitted on 29 Mar 2021

HAL is a multi-disciplinary open access archive for the deposit and dissemination of scientific research documents, whether they are published or not. The documents may come from teaching and research institutions in France or abroad, or from public or private research centers.
L'archive ouverte pluridisciplinaire HAL, est destinée au dépôt et à la diffusion de documents scientifiques de niveau recherche, publiés ou non, émanant des établissements d'enseignement et de recherche français ou étrangers, des laboratoires publics ou privés. 


\section{IS PHYSICAL FITNESS ASSOCIATED WITH THE TYPE OF ATTENDED SCHOOL? A CROSS-SECTIONAL ANALYSIS AMONG 20.000 ADOLESCENTS}

Martine Duclos ${ }^{\mathrm{a}, \mathrm{b}, \mathrm{c}}$, Philippe Lacomme ${ }^{\mathrm{d}}$, Celine Lambert ${ }^{\mathrm{e}}$, Bruno Pereira ${ }^{\mathrm{e}}$, Libo Ren ${ }^{\mathrm{f}}$, Gerard Fleury $^{\mathrm{d}}$, Hervé Ovigneur ${ }^{\mathrm{g}}$, Thibault Deschamps ${ }^{\mathrm{g}}$, Nicole Fearnbach ${ }^{\mathrm{h}}$, Jérémy Vanhelst ${ }^{\mathrm{k}, \mathrm{l}}$, JeanFrançois Toussaint ${ }^{\mathrm{i}}$, David Thivel ${ }^{\mathrm{b}} \mathrm{j}^{*}$ 


\begin{abstract}
Background. While academic achievement has been associated with physical activity, the present work questions the potential association between the physical fitness level of adolescents and the type of school they attend, ranging from academic to technical schools. Methods. 20,228 young French students from 76 schools (9,196 females), mean age 15.8 \pm 1.8 years, performed the Diagnoform ${ }^{\odot}$ test. This dataset includes two higher education institutions $(\mathrm{n}=870), 37$ general high schools $(\mathrm{n}=13,125), 18$ professional-oriented high schools $(n=3,569), 5$ agricultural high schools $(n=132), 2$ vocational training centers $(n=202)$ and 12 rural vocational training centers $(n=1,137)$.

Results. In higher education institutions and general high schools, girls showed better performances for all physical tests. A decreasing Quotient of overall Physical fitness Condition (QPC) was observed for both genders from urban higher education schools to rural and technical institutions $(\mathrm{p}<0.001)$. The proportion of total variance accounting for within institution variation is strong (intra-class correlation coefficients (ICC) 0.20 [0.15; 0.27] for QPC).
\end{abstract}

Conclusion. The lower physical fitness level observed here among students from technical or training schools places them at higher risks for the development of future chronic diseases. These results suggest that specific interventions are needed depending on the educational setting.

Key-words: cardiorespiratory fitness, muscular fitness, adolescents, health, academic achievement, type of schools 


\section{INTRODUCTION}

Physical fitness is a modifiable factor that may influence health. Systematic reviews concluded that physical fitness (both cardiorespiratory fitness (CRF) and muscular fitness) is considered one of the most important health markers, as well as a predictor of morbidity and mortality for cardiovascular disease (CVD) and for all causes in adults ${ }^{1,2,3}$. In children and adolescents, a recent systematic review showed that higher physical fitness, especially CRF, during childhood and adolescence was associated with lower BMI, lower waist circumference, lower body fatness and a lower prevalence of metabolic syndrome later in life ${ }^{4}$. In addition, a recent review including the entire spectrum of school-aged children, ranging from 6 to 18 years, showed a consistent and positive association between CRF and academic achievement ${ }^{5}$. Similar results were obtained in another review that included both cross-sectional and longitudinal studies ${ }^{6}$. Muscle mass and strength are also important for overall health. A prospective cohort study of 38,588 Swedish men aged 18 years showed an association between higher muscle strength and lower risk for future CVD events, independent of well-known risk factors such as low CRF, smoking and BMI until late middle age (up to 40 years of follow-up) ${ }^{7}$. An increased risk of middle age CVD mortality was also reported in men with low muscle strength, independent of common risk factors ${ }^{7}$.

Globally, in children and adolescents, overall physical fitness has been found associated with several factors such as gender, weight status, accommodation's neighborhood and geographical location for instance, but also with level of parental education and with the family socioeconomic status ${ }^{8-11}$. Similarly, there is a clear association between the parents' socioeconomic level, their academic curriculum and their implication into their kids' education, with their children's academic achievement ${ }^{12,13}$. This particularly important since 
education and income are associated with mortality ${ }^{14}$ as well as with other health outcomes later in life ${ }^{15}$.

In France, pupils from the 7th to the 9th grade with low academic performance are often encouraged to follow a technical curriculum in technical schools, which are of shorter duration and predominantly include manual and practical teaching. Since, the life expectancy of blue collar workers is 13 years shorter than that of white collar workers, most of these students are therefore at risk for reduced life expectancy ${ }^{16}$. Although there is a growing body of literature linking physical activity and CRF with academic achievement in children and adolescents, there is, to our knowledge, no study that has examined the association between physical fitness and the type of school attended. Properly identifying whether the type of school attended is associated with fitness impairments might help develop appropriate educational strategies from adolescence to potentially counteract the differences observed between individuals working in different occupational domains.

\section{METHODS AND METHODS}

\section{Participants}

Participants were recruited between April 2009 and March 2016 during scholar events, in eight sub-regions of the French former Rhône-Alpes region. These events were organized on a voluntary basis at the request of municipal councilors or directors of institutions. Different types of institutions were included: higher education institutions (school type 1), general high schools (school type 2), professional-oriented high schools (school type 3), agricultural high schools (school type 4), vocational training centers (school type 5) and rural vocational training centers (school type 6). When an institution volunteered, all classes were involved. The objective was to assess the physical capacity of students and to improve their knowledge 
regarding the preventive role of sports participation and physical activities. Data were collected in accordance with the Helsinki principles for human research as requested by the ethical authorities (CNIL number 1232206).

\section{Procedure}

The Diagnoform ${ }^{\circledR}$ Tonic physical test, developed by the Rhône-Alpes Athletic Federation and previously shown to be valid and reproducible ${ }^{17}$, was used to assess physical fitness of a French population $(n=31,349)$ in 22 regions of France, offering an important monitoring tool in the general population ${ }^{18}$. For the current analysis, we used the results of the Diagnoform in a subsample of 20,228 young French students from 76 schools. The study sample (Table 1) consisted of 20,228 young students (9,196 females and 11,032 males), aged 15.8 \pm 1.8 years (girls: $15.8 \pm 2.0$ years, boys: $15.8 \pm 1.6$ years, $\mathrm{p}=0.98$ ), with an average BMI of $20.5 \pm 2.9 \mathrm{~kg} / \mathrm{m}^{2}$ (girls: $20.2 \pm 2.8 \mathrm{~kg} / \mathrm{m}^{2}$, boys: $20.7 \pm 3.0 \mathrm{~kg} / \mathrm{m}^{2}$ ). Participants were recruited from 76 institutions of the Rhône-Alpes county: 870 subjects from 2 higher education institutions (school type 1), 13,125 subjects from 37 general high schools (school type 2), 3,569 subjects from 18 professional-oriented high schools (school type 3), 1,325 subjects from 5 agricultural high schools (school type 4), 202 subjects from 2 vocational training centers (school type 5) and 1,137 subjects from 12 rural vocational training centers (school type 6). All measurements were collected by trained staff and the reporting was supervised by investigators.

\section{Instruments}

\section{Description of tests (35-40 min workshop)}


For better understanding of the Diagnoform ${ }^{\odot}$ results, the name of each test indicates the main related physical capacity. Each test composing the battery is described below and its reliability and validity indicated, as previously detailed ${ }^{19}$.

1. Cardiorespiratory fitness was evaluated using the non-progressive $20 \mathrm{~m}$ shuttle run (maximum distance reached during a $3 \mathrm{~min}$ run). This test has been validated against the $20-\mathrm{m}$ shuttle run reference test from Leger et al (1988) $(r=0.78 ; P=0.001)$ and showed a good reliability (0.84). The adolescent ran back and forth on a straight $20 \mathrm{~m}$ line for $3 \mathrm{~min}$. The supervisor counted the number of times the adolescent went back and forth and translated it to a measurement, expressed in meters.

2. Coordination/Endurance. This standardized motor coordination-endurance test provides both a qualitative and quantitative evaluation of the student's motor competence. Adolescents performed a maximal number of sprint hops over a cross following a predefined sequence for a session of 30 seconds. Only successful sequences were counted. A good reliability was also found for this component $(0.81)$.

3: Agility/Coordination. It refers to the participant's ability to perform five consecutive strides (total length in centimeters for the five consecutive strides). The reliability for this test was excellent (0.90).

4: Lower muscular strength was assessed by the standing broad jump test. The adolescent jumped as far as possible with legs together. Results was recorded in $\mathrm{cm}$. This test showed a good reliability $(0.84)$.

5: Lower muscular endurance. A repeated squat jump test measured quadriceps strength, endurance and fatigue. The subjects had to perform five consecutive jumps with legs together, and results were recorded in $\mathrm{cm}$. 
6: Speed/Agility. A motor coordination test recording the minimal time needed to complete the $4 \times 10 \mathrm{~m}$ shuttle run. Time was recorded in second. An excellent reliability was found for the $4 \times 10 \mathrm{~m}$ shuttle run in adolescent $(0.90)$.

7: Speed. The anaerobic capacity is measured by running a $30 \mathrm{~m}$ linear course as fast as possible and results were recorded in seconds. This test showed a good reliability (0.85).

8: Upper muscular endurance. Subjects were asked to perform push-ups (muscular strength and endurance) with knees on the ground, lowering body to a $90^{\circ}$ elbow angle and then back up to the initial position (number of maximal push-ups without break). A good reliability was found for this test $(0.81)$.

The results of each test were analyzed in absolute value and also transformed to a normalized score from 1 (poor) to 20 (excellent). The mean of the normalized values across the 8 tests was calculated to create the Quotient of Physical Condition (QPC), a global indicator of individual physical fitness.

\section{Data analysis}

Statistical analysis was performed using Stata software (version 13; StataCorp, College Station, Texas, USA) and R3.3.1 (http://cran.r-project.org/). All tests were two-sided, with a Type I error set at 0.05 and all analyses were performed on the whole population and by sex. Continuous variables were expressed as mean \pm standard and categorical variables as frequencies and associated percentages. Internal consistency was assessed using Cronbach's alpha, item-total correlation and item-rest correlation (correlation between an item and the scale formed by all other items). Cronbach's alphas were calculated for all the scales and by removing each item, one after the other. Associations between physical test items and QPC were assessed with Pearson's or Spearman's correlation coefficient according to statistical distribution (the Gaussian distribution was verified by the Shapiro-Wilk test). All results 
related to the reliability of the Diagnoform ${ }^{\odot}$ test battery are presented as a supplementary file. Because observations from the same cluster (= institution) are usually more similar to each other than observations from different clusters, comparisons between the six school-types were performed with linear mixed models to take into account the dependencies among cluster members. The ratio of the between-cluster variance to the total variance, called "intraclass correlation coefficient" (ICC), was calculated to measure how individuals within a cluster are similar to one another. Analyzes covering the entire sample were adjusted for sex, age and BMI; and those relating to the samples of girls and boys were adjusted for age and BMI.

\section{RESULTS}

The Table 2 presents the results from a multivariate analysis considering gender, age and BMI for the total population and then age and BMI in boys and girls separately (The results from a univariate analysis are proposed in the supplementary Table S2). Average physical fitness score (QPC) was $47.3 \pm 16.1$ out of 100 (girls: $35.4 \pm 10.8$, boys: $57.3 \pm 12.6$ ). Significant differences were found between the type of school and physical fitness (Table 2), with a decreasing value of QPC from higher education institutions to more technical schools in both genders. Among girls, QPC was significantly higher in higher education institutions $(43.8 \pm 13.5)$ and in general high schools $(37.1 \pm 10.0)$ compared with all other types of schools $(\mathrm{p}<0.001)$. Among boys, QPC was significantly higher in higher education institutions (71.2 \pm 8.8$)$ than in all other types of schools where the average QPC were lower than 60 $(\mathrm{p}<0.001)$. In higher education institutions and general high schools, girls presented better performances for all physical tests. Similar results were found for boys, except for strength/speed. 
Results regarding the reliability of the Diagnoform ${ }^{\odot}$ tests battery reliability are presented as supplementary files (Table S1 and Figure S1).

\section{DISCUSSION}

The aim of this study was to investigate whether the type of school attended by French adolescents (high schools vs technical or training school) might be associated with their physical fitness level. According to our results, boys and girls of higher educational institutions show higher physical fitness compared with their peers from technical schools. As every component of physical fitness has prognostic value for present and future health, students of technical or training schools appear then at higher risk for future chronic diseases, calling for specific interventions to improve their fitness level.

In France, depending on academic results, students are oriented either towards technical or academics schools. Numerous factors are involved in the capacity to reach high academic performance and high diplomas. Among them, academic results, intellectual capacities, health status and socio-economic status are well recognized factors ${ }^{20}$. But for the last couple of years, CRF has emerged as another potential contributing factor ${ }^{21}$.

Our results show a difference in physical fitness between the types of academic schools in both genders. In higher education institutions and general high schools, girls presented better performances for all physical tests than in technical schools. Similar results were found for boys (except strength/speed). In other words, boys and girls of higher educational institutions have higher physical fitness (CRF, musculo-skeletal, motor fitness, coordination) than their peers from technical schools.

In youth, physical fitness is considered as an important marker of health and is now considered one of the most important health indicators throughout the lifespan ${ }^{22}$. For children 
and adolescents, higher CRF is associated with a healthier cardiovascular profile ${ }^{23}$ and a healthier body composition ${ }^{22,24}$ later in life and improvements in CRF are associated with reduced mortality risk in adults ${ }^{2}$. Muscular fitness has been increasingly recognized in the prevention of chronic disease and has been inversely associated with established and emerging CVD risk factors in adolescents ${ }^{25,26}$.

While about half of the variance in CRF is considered to be attributable to heritable factors ${ }^{27}$, the other half is influenced by several factors, including body fatness, growth, sexual maturation, age, sex, health status, yet its principal modifiable determinants are moderate-tovigorous PA (MVPA) and sedentary behavior ${ }^{28}$. Although we controlled for several potential confounders such as age, growth, pubertal status and health status, it cannot be excluded that other confounders such as genetics and body composition differed, despite similar BMI.

We hypothesized that sedentary activity time would be lower in technical schools since students are involved in manual classes that often imply a standing position (passive or active), while higher academic classes usually lead students to accumulate a higher total sitting time (during classes and homework hours). Structured PA such as extracurricular sports was recorded and was not significantly different between types of schools. However, habitual levels of PA were not recorded. It is noteworthy that previous studies have reported low levels of PA at this age, with PA among older adolescents matching those of 60-year-old individuals, providing strong evidence that adolescence represents a high-risk time period for physical inactivity ${ }^{29}$. In addition, several studies have reported little to no effect of family wealth on PA levels ${ }^{30,31}$. This is contrary to findings with physical fitness, as stressed in the HELENA study, where a strong positive association between socioeconomic status and physical fitness was reported in European adolescents (15.0 $1.3 \mathrm{yr})$ independently of body fat and objectively assessed $\mathrm{PA}^{32}$. Although the socio-economic status and income were not measured in the present study, the level of education is considered as a socio-economic 
marker. At a population level, manual occupation is associated with lower socio-economic status compared to intellectual occupation.

School types 3 to 6 will lead to manual professions (blue-collar workers of both urban and rural environment and agriculture). In France, life expectancy of blue collar workers is 13 years shorter than that of white collar workers ${ }^{16}$. These results come from associations with working conditions, health behavior (including PA and nutrition) and health care ${ }^{15}$. As physical fitness is associated with health outcomes ${ }^{33}$ and as our results show for the first time that a difference already exists between 16-year-old students of academic and technical schools, it is necessary to develop preventive strategies such as the promotion of PA in these youth before they start their professional lives. Importantly, sedentary behavior is already known to increase during adulthood, and PA habits and CRF in youth track into adulthood $^{34,35}$. Therefore, designing specific interventions targeting physical fitness in technical school students are warranted.

Finally, the high intra-class correlation coefficients (ICC) values highlighted great withinschool correlations between participants. Therefore, for more efficient physical fitness promotion, school-specific PA programs should be designed.

We usually consider mortality, or the presence of chronic disease, to be a standard, objective health indicator ${ }^{36}$. Alternative health measures such as CRF or muscle strength may be better predictors of health status and targets for the prevention of chronic disease ${ }^{33}$. These indicators improve quickly with regular PA.

PA and sedentary behaviors are difficult to measure with reliability using self-reported questionnaires, as they are prone to overestimation biases ${ }^{37}$ and have a low to moderate correlation with objective measures of $\mathrm{PA}^{37,38}$. Accelerometers devices remain however expensive and require specific scientific and technical skills. Moreover, most commercial devices are not reproducible, valid, or accurate ${ }^{39,40}$. By contrast, physical fitness is an 
objective and accurate measure, representing usual PA. Moreover, as stated by Van der Velde $^{41}$, the relative importance of high PA for cardiometabolic health should consider the mediating role of $\mathrm{CRF}$, explaining $73 \%$ of the association between moderate-to-vigorous PA and metabolic risk. In the present study, the high correlation between QPC and Agility, strength/speed and endurance/strength in both girls and boys, and the fact that these three tests decrease progressively from higher education institutions to more technical schools in both genders suggest that these three physical fitness components may be good proxies of overall physical fitness in large segments of population.

The present study has important strengths, including the large sample size and the careful harmonization of anthropometric and fitness assessment techniques throughout the study, including demonstrated reliability ${ }^{18}$. However, our results have to be considered in light of some limitations. First, it was limited to the Rhône-Alpes region and might not be nationally representative. However, due to the homogeneity of educational program in France it is unlikely that the results will be different between regions. The absence of measures of habitual PA level could interfere with the results but, as discussed, CRF is more accurate than PA questionnaires and the effect of CRF on health are independent of the effects of PA. Previous studies also show that at this age, adolescent PA has steadily declined ${ }^{29}$. Although gender, BMI and age are considered in the present analysis, other factors could have impacted our results and should have been considered, such as the socio-economical status of the participants, their family culture toward PA, their potential implication in extra-school regular physical activities, the school infrastructures or geographical location, among others. This has to be considered here as a limitation of the present analysis. Importantly, it would have been also interesting to have information regarding the participants' level of physical fitness before their integration in these particular school types, which was unfortunately not possible in the present study. 
As any cross-sectional study, we cannot state the direction of the interaction and it must be noted that the adolescents' physical fitness level is not the primary or sole determinant of school academic status in high school students. According to a recent review from the U.S. Department of Health and Human Services ${ }^{21}$ insufficient evidence is available to determine whether a relationship exists between moderate-to-vigorous PA and cognition in adolescents ages 14 to 18 years (although "all studies reported positive results, but the difficulty to conclude mainly relies on the insufficient number of studies and the difficulties to reliably study cognition",22).

\section{CONCLUSION}

The main finding of this study is that physical fitness is associated with the type of school that young students attend; 16 year old girls and boys of higher educational institutions have higher physical fitness (CRF, musculo-skeletal, motor fitness, coordination) than their peers from technical schools. As every component of physical fitness has prognostic value for present and future health, students of technical or training schools represent a group at higher risk of future chronic diseases. Specific attention is required regarding the evaluation and development of physical fitness in students attending technical schools, especially since physical fitness remains modifiable and since its components improve quickly with regular PA. We suggest the use of these three physical tests to establish physical fitness systematically in all provided education for students at the levels of 15-16 years. Future prospective studies should focus on evaluating in technical schools the potential benefits of improving physical fitness for future health of the professionals they produce.

Acknowledgments: The authors thank Pierre-Antoine Onfroy (LIMOS), Yoann Alvarez (LIMOS), Stéphane MARCHAND MAILLET and Rémi GOUBE (MGEN), Stéphanie 
FILIBERTO and Philippe COLLARD (Rhône-Alpes League of Athletism) for their full support.

Funding: this research did not receive any specific grant from funding agencies in the public, commercial, or not-for-profit sectors

Disclosure of interest. The authors report no conflict of interest

Authors' contribution. PL, CL, BP, LR, GF, HO and TD designed the study; PL, CL, BP, LR, GF, HO and TD collected the data; PL, CL, BP, LR, GF, HO and TD were in charge of the data management; MD, CL, BP and TD analyzed the data; MD, CL, BP, NF, JFT and TD wrote the manuscript; MD, PL, CL, BP, LR, GF, HO, TD, NF, JFT and TD reviewed and cowrote the manuscript. All the authors read and approved the final version of the manuscript.

\section{References}

1. Myers J, Prakash M, Froelicher V, Do D, Partington S, Atwood JE. Exercise capacity and mortality among men referred for exercise testing. N Engl J Med. 2002;346(11):793-801. 2. Lee DC, Artero EG, Sui X, Blair SN. Mortality trends in the general population: the importance of cardiorespiratory fitness. J Psychopharmacol. 2010;24(4 Suppl):27-35.

3. Leong DP, Teo KK, Rangarajan S, Lopez-Jaramillo P, Averzum A, et al. Prognostic value of grip strength: findings from the Prospective Urban Rural Epidemiology (PURE) study. Lancet 2015;386(9990):266-73.

4. Mintjens S, Menting MD, Daams JG, van Poppel MNM, Roseboom TJ, Gemke RJBJ. Cardiorespiratory Fitness in Childhood and Adolescence Affects Future Cardiovascular Risk Factors: A Systematic Review of Longitudinal Studies. Sports Med 2018;48(11):2577-605.

5. Marques A, Mota J, Gaspar T, Gaspar de Matos M. Associations between selfreported fitness and self-rated health, life-satisfaction and health-related quality of life among adolescents. J Exerc Sci Fit 2017;15(1):8-11.

6. Santana CCA, Azevedo LB, Cattuzzo MT, Hill JO, Prado WL. Physical fitness and academic performance in youth: A systematic review. Scand J Med Sci Sports. 2017;27(6):579-603.

7. Timpka S, Petersson IF, Zhou C, Englund M. Muscle strength in adolescent men and risk of cardiovascular disease events and mortality in middle age: a prospective cohort study. BMC Medicine. 2014;12:62.

8. Rodrigues D, Padez C, Machado-Rodrigues AM. Environmental and Sociodemographic Factors Associated with 6-10-Year-Old Children's School Travel in Urban and Non-urban Settings. J Urban Health. 2018; 95(6): 859-868. 
9. Quinn TD, Wu F, Mody D, Bushover B, Mendez DD, Schiff M, Fabio A. Associations Between Neighborhood Social Cohesion and Physical Activity in the United States, National Health Interview Survey, 2017. Prev Chronic Dis. 2019; 16: E163.

10. Da Silva J, Andrade A, Capistrano R, Lisboa T, Andrade RD, Pereira Gomes Felden E, Beltrame TS. [Insufficient levels of physical activity of adolescents associated with sociodemographic, environmental and school factors]. Cien Saude Colet. 2018; 12: 4277 4288 .

11. Janssen A, Leahy AA, Diallo TMO, Smith JJ, Kennedy SG, Eather N, Mavilidi MF, Wagemakers A, Babic MJ, Luband DR. Cardiorespiratory fitness, muscular fitness and mental health in older adolescents: A multi-level cross-sectional analysis. Preventive Medicine. 2020; 132: 105985.

12. Zhang F, Jiang Y, Ming H, Ren Y, Wang L, Huang S. Family socio-economic status and children's academic achievement: The different roles of parental academic involvement and subjective social mobility. Br J Educ Psychol. 2020; 90(3): 561-579.

13. Guo X, Ly B, Zhou H, Liu C, Liu J, Jiang K, Luo L. Gender Differences in How Family Income and Parental Education Relate to Reading Achievement in China: The Mediating Role of Parental Expectation and Parental Involvement. Front Psychol. 2018; 9: 783.

14. Martikainen P, Makela P, Peltonen R, Myrskyla M. Income differences in life expectancy: the changing contribution of harmful consumption of alcohol and smoking. Epidemiology 2014;25(2):182-90.

15. Van Ourti T, van Doorslaer E, Koolman X. The effect of income growth and inequality on health inequality: Theory and empirical evidence from the European Panel. $\mathrm{J}$ Health Econ 2009;28(3):525-39.

16. Blanpain N. L'espérance de vie par niveau socio-économique. INSEE 2018.

17. Mouraby HT, Nassif H, Toussaint JF, Desgorces FD. Reliability and validity of Diagnoform fitness test procedure. Science Sports. 2011;27:4.

18. Nassif H, Sedeaud A, Abidh E, Schipman J, Tafflet M, Deschamps T, et al. Monitoring fitness levels and detecting implications for health in a French population: an observational study. BMJ Open. 2012;2(5).

19. Mouraby R, Tafflet M, Nassif H, Toussaint JF, Desgorces FD. Fiabilité et validation de la batterie de tests physiques Diagnoform. Sci sports. 2011; 10: 1016.

20. Esteban-Cornejo I, Tejero-Gonzalez CM, Sallis JF, Veiga OL. Physical activity and cognition in adolescents: A systematic review. J Sci Med Sport. 2015;18(5):534-9.

21. Committee PAGA. Physical Activity Guidelines Advisory Committee Scientific Report

Washington, DC: US Department of Health and Human Services, 2018.

22. Ortega FB, Ruiz JR, Castillo MJ, Sjostrom M. Physical fitness in childhood and adolescence: a powerful marker of health. Int J Ob 2008;32(1):1-11.

23. Ruiz JR, Huybrechts I, Cuenca-Garcia M, Artero EG, Labayen I, Meirhaeghe A, et al. Cardiorespiratory fitness and ideal cardiovascular health in European adolescents. Heart 2015;101(10):766-73. 
24. Moliner-Urdiales D, Ruiz JR, Ortega FB, Rey-Lopez JP, Vincente-Rodriguez G, Espana-Romero V, et al. Association of objectively assessed physical activity with total and central body fat in Spanish adolescents; the HELENA Study. Int J Ob 2009;33(10):1126-35. 25. Steene-Johannessen J, Anderssen SA, Kolle E, Andersen LB. Low muscle fitness is associated with metabolic risk in youth. Med Sci Sports Exerc. 2009;41(7):1361-7.

26. Artero EG, Ruiz JR, Ortega FB, Espana-Romero V, Vincente-Rodriguez G, Molnar D, et al. Muscular and cardiorespiratory fitness are independently associated with metabolic risk in adolescents: the HELENA study. Pediatr Diabetes. 2011;12(8):704-12.

27. Bouchard C, An P, Rice T, Skinner JS, Wilmore JH, Gagnon J, et al. Familial aggregation of $\mathrm{VO} 2$ max response to exercise training: results from the HERITAGE family study. J Appl Physiol 1999;87(3):1003-8.

28. Teran-Garcia M, Rankinen T, Bouchard C. Genes, exercise, growth, and the sedentary, obese child. J Appl Physiol 2008;105(3):988-1001.

29. Varma VR, Dey D, Leroux A, Junrui DI, Urbanek J, Xiao L, et al. Re-evaluating the effect of age on physical activity over the lifespan. Prev Med 2017;101:102-8.

30. Jimenez Pavon D, Ortega FP, Ruiz JR, Espana-Romero V, Garcia-Artero E, Moliner Urdiales D, et al. Socioeconomic status influences physical fitness in European adolescents independently of body fat and physical activity: the HELENA study. Nutr Hosp. 2010;25(2):311-6.

31. Costa-Tutusaus L, Guerra-Balic M. Relationship between Healthy Lifestyle and Sociodemographic Factors in Adolescents in Catalonia: Application of VISA-TEEN Questionnaire. PloS One. 2016;11(9):e0163381.

32. De Cocker K, Ottevaere C, Sjostrom M, Moreno LA, Warnberg J, Valtuena J, et al. Self-reported physical activity in European adolescents: results from the HELENA (Healthy Lifestyle in Europe by Nutrition in Adolescence) study. Public Health Nutr. 2011;14(2):24654.

33. Ross R, Blair SN, Arena R, Church TS, Despres JP, Franklin BA, et al. Importance of Assessing Cardiorespiratory Fitness in Clinical Practice: A Case for Fitness as a Clinical Vital Sign: A Scientific Statement From the American Heart Association. Circulation. 2016;134(24):e653-e99.

34. Biddle SJ, Pearson N, Ross GM, Braithwaite R. Tracking of sedentary behaviours of young people: a systematic review. Prev Med. 2010;51(5):345-51.

35. Telama R. Tracking of physical activity from childhood to adulthood: a review. Obes Facts. 2009;2(3):187-95.

36. Hoffmann R, Hu Y, de Gelder R, Menvielle G, Bopp M, Mackenbach JP. The impact of increasing income inequalities on educational inequalities in mortality - An analysis of six European countries. Int J Equity Health 2016;15(1):103.

37. Prince SA, Adamo KB, Hamel ME, Hardt J, Gorber SC, tremblay M. A comparison of direct versus self-report measures for assessing physical activity in adults: a systematic review. Int J Behav Nutr Phys Act. 2008;5:56.

38. Steene-Johannessen J, Anderssen SA, van der Ploeg HP, Hendriksen IJM, Donnelly AE, Brage S, et al. Are Self-report Measures Able to Define Individuals as Physically Active or Inactive? Med Sci Sports Exerc. 2016;48(2):235-44. 
39. Wallen MP, Gomersall SR, Keating SE, Wisloff U, Coombes JS. Accuracy of Heart Rate Watches: Implications for Weight Management. PloS One. 2016;11(5):e0154420.

40. Guidoux R, Duclos M, Fleury G, Lacomme P, Lamaudière N, Saboul D, et al. The eMouveRecherche application competes with research devices to evaluate energy expenditure, physical activity and still time in free-living conditions. J Biomed Inform. 2017;69:128-34.

41. van der Velde J, Schaper NC, Stehouwer CDA, van der Kallen CJH, Sep SJS, Schram MT, et al. Which is more important for cardiometabolic health: sedentary time, higher intensity physical activity or cardiorespiratory fitness? The Maastricht Study. Diabetologia 2018;61(12):2561-9.

\section{TABLES}

Table 1: Descriptive analysis

\begin{tabular}{|c|c|c|c|}
\hline & $\begin{array}{r}\text { Total } \\
(\mathrm{n}=\mathbf{2 0 , 2 2 8})\end{array}$ & $\begin{array}{r}\text { Girls } \\
(n=9,196)\end{array}$ & $\begin{array}{r}\text { Boys } \\
(\mathrm{n}=11,032)\end{array}$ \\
\hline \multicolumn{4}{|l|}{ Characteristics of students } \\
\hline Age (years) & $15.8 \pm 1.8$ & $15.8 \pm 2.0$ & $15.8 \pm 1.6$ \\
\hline $\mathrm{BMI}\left(\mathrm{kg} / \mathrm{m}^{2}\right)$ & $20.5 \pm 2.9$ & $20.2 \pm 2.8$ & $20.7 \pm 3.0$ \\
\hline \multicolumn{4}{|l|}{ School type } \\
\hline higher education institutions & $870(4.3)$ & $314(3.4)$ & $556(5.1)$ \\
\hline general high schools & $13,125(64.9)$ & $6,237(67.8)$ & $6,888(62.4)$ \\
\hline professional-oriented high schools & $3,569(17.6)$ & $1,647(17.9)$ & $1,922(17.4)$ \\
\hline agricultural high schools & $1,325(6.6)$ & $553(6.0)$ & $772(7.0)$ \\
\hline vocational training centers & $202(1.0)$ & $0(0.0)$ & $202(1.8)$ \\
\hline rural vocational training centers & $1,137(5.6)$ & $445(4.9)$ & $692(6.3)$ \\
\hline \multicolumn{4}{|l|}{ Diagnoform $@$ Tonic physical test } \\
\hline Endurance (m) & $560 \pm 87$ & $508 \pm 70$ & $604 \pm 74$ \\
\hline Coordination/endurance (number) & $30.4 \pm 7.8$ & $29.4 \pm 7.3$ & $31.2 \pm 8.0$ \\
\hline Coordination $(\mathrm{cm})$ & $971 \pm 164$ & $862 \pm 118$ & $1,062 \pm 139$ \\
\hline Strength/speed $(\mathrm{cm})$ & $176 \pm 39$ & $149 \pm 30$ & $198 \pm 32$ \\
\hline
\end{tabular}




\begin{tabular}{lrrr}
\hline & $\begin{array}{r}\text { Total } \\
(\mathbf{n = 2 0 , 2 2 8})\end{array}$ & $\begin{array}{r}\text { Girls } \\
(\mathbf{n = 9 , 1 9 6 )}\end{array}$ & $\begin{array}{r}\text { Boys } \\
(\mathbf{n = 1 1 , 0 3 2})\end{array}$ \\
\hline Endurance/strength (cm) & $882 \pm 199$ & $744 \pm 135$ & $997 \pm 168$ \\
Speed/coordination (sec) & $11.1 \pm 1.5$ & $11.9 \pm 1.4$ & $10.5 \pm 1.2$ \\
Speed (sec) & $5.0 \pm 0.8$ & $5.3 \pm 0.8$ & $4.6 \pm 0.7$ \\
Strength (number of repetitions) & $34.6 \pm 21.1$ & $22.0 \pm 12.9$ & $45.1 \pm 21.0$ \\
Quotient of physical condition $(/ 100)$ & $47.3 \pm 16.1$ & $35.4 \pm 10.8$ & $57.3 \pm 12.6$
\end{tabular}

Data are presented as frequencies (associated percentages) or as mean \pm standard deviation.

BMI: body mass index.

Table 2: Physical performance according to school types.

\begin{tabular}{lcccccc}
\hline & School-type 1 & School-type 2 & School-type 3 & School-type 4 & School-type 5 & School-type 6 \\
\hline Total & $\mathrm{n}=870$ & $\mathrm{n}=13,125$ & $\mathrm{n}=3,569$ & $\mathrm{n}=1,325$ & $\mathrm{n}=202$ & $\mathrm{n}=1,137$ \\
QPC & $61.3 \pm 17.0$ & $48.3 \pm 15.2$ & $43.6 \pm 16.8^{\mathbf{a b}}$ & $42.6 \pm 16.0^{\mathbf{a}}$ & $53.2 \pm 11.8$ & $42.2 \pm 15.5^{\mathbf{a b}}$ \\
En & $626 \pm 86$ & $565 \pm 80^{\mathbf{a}}$ & $537 \pm 99^{\mathbf{a b}}$ & $541 \pm 84^{\mathbf{a}}$ & $588 \pm 71^{\mathbf{a}}$ & $548 \pm 83^{\mathbf{a}}$ \\
CoEn & $34.6 \pm 8.4$ & $31.1 \pm 7.7$ & $28.1 \pm 7.5^{\mathbf{a b}}$ & $29.0 \pm 7.2^{\mathbf{a}}$ & $27.4 \pm 7.9^{\mathbf{a}}$ & $28.2 \pm 6.6^{\mathbf{a b}}$ \\
Co & $1,067 \pm 166$ & $977 \pm 157$ & $946 \pm 175^{\mathbf{b}}$ & $929 \pm 172^{\mathbf{b}}$ & $1,051 \pm 133$ & $938 \pm 159^{\mathbf{b}}$ \\
StSp & $199 \pm 40$ & $176 \pm 38$ & $170 \pm 42^{\mathbf{b}}$ & $169 \pm 41$ & $198 \pm 36$ & $170 \pm 39^{\mathbf{b}}$ \\
EnSt & $1,035 \pm 201$ & $889 \pm 189$ & $841 \pm 213^{\mathbf{a b}}$ & $838 \pm 205^{\mathbf{a}}$ & $1,000 \pm 173$ & $848 \pm 182^{\mathbf{a b}}$ \\
SpCo & $10.1 \pm 1.3$ & $11.0 \pm 1.4$ & $11.3 \pm 1.7^{\mathbf{a b}}$ & $11.4 \pm 1.4$ & $10.9 \pm 1.3$ & $11.6 \pm 1.4^{\mathbf{a b}}$ \\
Sp & $4.4 \pm 0.8$ & $4.9 \pm 0.8$ & $5.1 \pm 1.0$ & $5.2 \pm 0.9$ & $5.0 \pm 1.2$ & $5.3 \pm 0.9^{\mathbf{a b c}}$ \\
St & $50.3 \pm 24.3$ & $35.4 \pm 21.0^{\mathbf{a}}$ & $30.5 \pm 20.2^{\mathbf{a b}}$ & $29.4 \pm 18.1^{\mathbf{a b}}$ & $42.8 \pm 17.2$ & $30.6 \pm 20.1^{\mathbf{a b}}$ \\
Girls & $\mathrm{n}=314$ & $\mathrm{n}=6,237$ & $\mathrm{n}=1,647$ & $\mathrm{n}=553$ & $\mathrm{n}=0$ & $\mathrm{n}=445$ \\
QPC & $43.8 \pm 13.5$ & $37.1 \pm 10.0^{\mathbf{a}}$ & $30.6 \pm 10.4^{\mathbf{a b}}$ & $29.6 \pm 10.1^{\mathbf{a b}}$ & - & $29.6 \pm 9.7^{\mathbf{a b}}$ \\
En & $553 \pm 71$ & $518 \pm 64^{\mathbf{a}}$ & $475 \pm 79^{\mathbf{a b}}$ & $487 \pm 73^{\mathbf{a}}$ & - & $490 \pm 69^{\mathbf{a c}}$ \\
CoEn & $32.8 \pm 8.3$ & $30.1 \pm 7.3$ & $26.8 \pm 7.0^{\mathbf{a b}}$ & $27.9 \pm 6.2^{\mathbf{a b}}$ & - & $28.0 \pm 6.4^{\mathbf{a b}}$ \\
Co & $909 \pm 131$ & $875 \pm 113$ & $830 \pm 118^{\mathbf{a b}}$ & $803 \pm 117^{\mathbf{a b}}$ & - & $825 \pm 116^{\mathbf{a b}}$ \\
StSp & $160 \pm 30$ & $152 \pm 29$ & $142 \pm 29^{\mathbf{a b}}$ & $137 \pm 29$ & - & $141 \pm 29^{\mathbf{a b}}$ \\
EnSt & $830 \pm 142$ & $760 \pm 128^{\mathbf{a}}$ & $694 \pm 138^{\mathbf{a b}}$ & $686 \pm 133^{\mathbf{a b}}$ & - & $714 \pm 127^{\mathbf{a b c}}$ \\
SpCo & $11.2 \pm 1.1$ & $11.7 \pm 1.3$ & $12.2 \pm 1.6^{\mathbf{a b}}$ & $12.3 \pm 1.3^{\mathbf{a}}$ & - & $12.4 \pm 1.3^{\mathbf{a b}}$ \\
Sp & $5.1 \pm 0.7$ & $5.2 \pm 0.7$ & $5.6 \pm 1.0$ & $5.6 \pm 0.8$ & - & $5.8 \pm 0.9^{\mathbf{a b c}}$ \\
St & $31.5 \pm 14.2$ & $23.2 \pm 12.9^{\mathbf{a}}$ & $18.3 \pm 11.6^{\mathbf{a b}}$ & $18.1 \pm 11.8^{\mathbf{a b}}$ & - & $17.6 \pm 11.2^{\mathbf{a b}}$ \\
Boys & $\mathrm{n}=556$ & $\mathrm{n}=6,888$ & $\mathrm{n}=1,922$ & $\mathrm{n}=772$ & $\mathrm{n}=202$ & $\mathrm{n}=692$ \\
QPC & $71.2 \pm 8.8$ & $58.3 \pm 11.7$ & $54.7 \pm 12.8$ & $51.9 \pm 12.6^{\mathbf{a b}}$ & $53.2 \pm 11.8$ & $50.3 \pm 12.9^{\mathbf{a b c}}$ \\
\hline
\end{tabular}




\begin{tabular}{lcccccc}
\hline En & $668 \pm 63$ & $608 \pm 69$ & $589 \pm 83$ & $579 \pm 70^{\mathbf{a b}}$ & $588 \pm 71$ & $586 \pm 68$ \\
CoEn & $35.5 \pm 8.2$ & $32.0 \pm 7.9$ & $29.2 \pm 7.8^{\mathbf{b}}$ & $29.7 \pm 7.8$ & $27.4 \pm 7.9$ & $28.3 \pm 6.7^{\mathbf{b}}$ \\
Co & $1,156 \pm 106$ & $1,069 \pm 132$ & $1,045 \pm 154$ & $1,020 \pm 145$ & $1,051 \pm 133$ & $1,011 \pm 138^{\mathbf{b}}$ \\
StSp & $221 \pm 26$ & $198 \pm 30$ & $194 \pm 36$ & $193 \pm 33$ & $198 \pm 36$ & $189 \pm 32$ \\
EnSt & $1,151 \pm 120$ & $1,006 \pm 158$ & $966 \pm 184^{\mathbf{a b}}$ & $947 \pm 176^{\mathbf{a b}}$ & $1,000 \pm 173$ & $934 \pm 159^{\mathbf{a b}}$ \\
SpCo & $9.6 \pm 0.9$ & $10.4 \pm 1.2$ & $10.6 \pm 1.4^{\mathbf{b}}$ & $10.8 \pm 1.2$ & $10.9 \pm 1.3$ & $11.0 \pm 1.2^{\mathbf{b}}$ \\
Sp & $4.1 \pm 0.5$ & $4.6 \pm 0.6$ & $4.7 \pm 0.9$ & $4.8 \pm 0.7$ & $5.0 \pm 1.2$ & $5.0 \pm 0.7^{\mathbf{b c}}$ \\
St & $60.9 \pm 22.3$ & $46.4 \pm 20.8$ & $41.0 \pm 20.0^{\mathbf{a b}}$ & $37.5 \pm 17.5^{\mathbf{a b}}$ & $42.8 \pm 17.2$ & $38.9 \pm 20.1^{\mathbf{a b}}$ \\
\hline
\end{tabular}

Data are presented as mean \pm standard deviation. School-type 1: higher education institutions; schooltype 2: general high schools; school-type 3: professional-oriented high schools; school-type 4: agricultural high schools; school-type 5: vocational training centers; school-type 6: rural vocational training centers. Co: coordination $(\mathrm{cm})$; CoEn: coordination-endurance (number); En: endurance $(\mathrm{m})$; EnSt: endurance-strength (cm); QPC: quotient of physical condition (/100); Sp: speed (sec); SpCo: speed-coordination (sec); St: strength (number of repetitions); StSp: strength-speed (cm).

Statistically significant difference compared to: a, school-type 1; b, school-type 2; c, school-type 3; d, school-type 4; e, school-type 5. Analyses were adjusted for: sex, age and body mass index ("total" analysis), or age and body mass index ("girls" and "boys" analyses). 